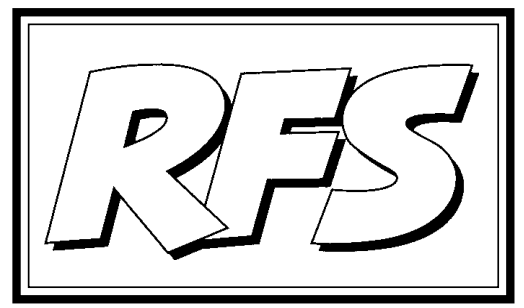

Revista de Fomento Social, 54 (1999), 379-392

\title{
El gran reto de África
}

En el acto de fin de carrera, y como despedida a sus alumnos, el profesor Rul-lán les invita a fijar su atención en la situación de África. Para ello dibuja un cuadro resumido de las sombras y las luces del «continente olvidado», poniendo especial énfasis en las tres esclavitudes que han sufrido sus habitantes: humana, colonial y económica. Concluye con un breve llamamiento a la cooperación, sobre todo en el campo de la formación.

(*) Profesor del Departamento de Economía, Ciencias Jurídicas y Sociología de la Facultad de Ciencias Económicas y Empresariales (ETEA), adscrita a la Universidad de Córdoba.

(1) El texto de la presente nota corresponde a la lección magistral de fin de carrera impartida en esta Facultad Córdoba, en octubre de 1999. Hemos optado por mantener las alusiones a ese preciso contexto de la versión original. El profesor Rul-lán es responsable de INTERMON en Córdoba y acababa de volver de Mali, donde estuvo para iniciar un trabajo de investigación sobre el éxodo rural de niñas a la capital, Bamako. 


\section{Introducción}

Acabo de llegar de África y estoy lleno de aquel maravilloso continente y, naturalmente, al pedirme que pronunciase la última lección de la carrera no se me ha ocurrido un tema mejor que aquello de lo que ahora estoy lleno: África y el reto que supone para nosotros su futuro.

Pero además hay tres razones importantes que justifican la elección de este tema para esta ocasión y éstos son:

Primero, que todos somos africanos.

Segundo, que todos somos hombres de empresa.

Tercero, que todos somos producto de ETEA.

TODOS SOMOS AFRICANOS. Hasta hace poco nuestra parienta más antigua de la que tenemos noticia era una mujer australopiteca que vivió hace unos cuatro millones y medio de años en el sur de Etiopía a la que llamábamos Lucy; pero en 1995 en el desierto de Chad se encontró parte del esqueleto de otro de nuestros antepasados todavía más antiguo al que los científicos llamaron «Abel». A lo largo de toda la costa de aquel continente han ido apareciendo restos de homínidos, lo que ha hecho que muchos admitiesen nuestro origen africano. Fue en aquel continente donde se echaron las raíces de nuestra familia humana. Blancos o negros todos somos de la misma familia y, por tanto, sería muy feo olvidar a nuestros parientes más pobres.

TODOS SOMOS HOMBRES DEEMPRESA. Vuestra formación durante los años que habéis pasado en esta institución ha tenido como objetivo último prepararos para el mundo de la empresa, y como hombres de empresa, lo primero que tendréis que aprender es que el mundo es mucho más grande que Córdoba y que Andalucía y que España y que la misma Europa. Se habla mucho de globalización y esto no es una moda; es una pura realidad: las finanzas y el comercio traspasan todas las fronteras y la mano de obra se mundializa, bien moviéndose físicamente de un país a otro, bien trabajando en su propio país para empresas del otro extremo de la tierra. Usamos en España ropa fabricada en Tailandia, zapatos de Corea, frigoríficos del Japón, tomamos el café de Colombia o el cacao de Madagascar. El mundo, todo el mundo, se ha convertido en un gran mercado y vosotros, futuros hombres de empresa, habéis de tener una visión universal y tenéis que estar dispuestos a ir a donde se abran oportunidades para vuestra empresa. Y os puedo asegurar que África, con sus 700 millones de habitantes, os está 
esperando. Mali, de donde acabo de llegar, está inundada de productos llegados de la China, pero de productos españoles sólo pude encontrar en un único supermercado el vino Don Simón y los zumos de fruta Zumosol...

TODOS SOMOS PRODUCTO DEETEA. Habéis estudiado en ETEA, y si por algo ha de caracterizarse el antiguo alumno de estainstitución ha de ser por una cierta ética empresarial,éticaque, en un mundo globalizadocomoel nuestro, necesariamente ha de incluir una seria preocupación por los problemas del subdesarrollo o, dicho en otras palabras, por el problema de la distribución de los frutos del trabajo. El fin de la empresa es generar riqueza transformando el mundo que nos rodea. Y mucha riqueza se está creando. Pero el gran problema del mundo actual es cómo distribuir estariqueza. Yeste problema dela distribución delariquezadebe preocuparacualquier chica o chico que haya pasado varios años en ETEA; de lo contrario, si la institución noha sidocapazde ayudara desarrollaresta concienciasocialen sus alumnosentonces, nodudoen afirmarlo,ETEA hafracasado, pormuy buenos que sean los conocimientos técnicos que haya impartido.

Justificado pues el tema de esta última lección, adentrémonos un poco, no en toda África, sino sólo en la África subsahariana.

¿Qué es esta África, cuna de nuestros antepasados, de la que sabemos tan poco? Vamos a olvidarnos por un momento de Tarzán, de los safaris fotográficos, de las fieras o del tam tam de la selva, y vamos a intentar adquirir una visión más objetiva, con sus luces y sombras, de este gran continente.

\section{Luces de África}

Las primeras noticias fidedignas que tenemos del África subsahariana nos vienen principalmente de los viajeros, cronistas y geógrafos árabes. En 1077, El Bekri, hijo de un gobernador árabe de Córdoba, escribe sobre el reino de Ghana, cuyo rey decía que era «el más rico de la tierra a causa de las minas de oro que controla». Ghana era el gran mercado de intercambio entre el mundo norteafricano y el sahariano, cuyas caravanas intercambiaban la sal traída del norte por el mijo, el oro y los esclavos del sur. Prueba de estas relaciones comerciales internacionales son los más antiguos monolitos funerarios grabados en España que se encuentran aún hoy en la ciudad de Gao, en el corazón de Mali. A principios del siglo XI aparece el imperio de Mali del que, como dice un cronista árabe, «salen cada año doce mil camellos camino del Cairo, cargados de granos y oro». Y a la famosa ciudad de 
Tombuctú llegan las caravanas del norte, convirtiendo esta ciudad en uno de los más importantes centros comerciales del continente. Al imperio de Mali le siguió el de Songhai, que llegó a ser tan grande como el de Carlomagno, extendiéndose desde Segou en el Níger hasta Dahomei, y llegando su fama hasta Europa que mandaba sus embajadores a este país africano. A finales del siglo XVI, el Sultán de Marruecos, Mulay Ahmed, apodado Al Mansur (el Victorioso), mandó a través del Sahara un ejército formado principalmente por españoles y al mando de un renegado también español, llamado (con perdón del público) Joder, por su costumbre en repetir este nombre, para conquistar Tombuctú.

Y mientras en la región del Sudán se desarrollaban estos reinos, en la parte oriental de África aparecían los reinos cristianos monofisitas de Nubia: Nobatia, Dongola y Aloa así como el importante imperio de Etiopía regido por el monarca que llevaba el título de Rey de Judá. Aquí tenemos una muestra de una historia de África no tan salvaje como generalmente nos imaginamos.

Vayamos a hora a su economía y veremos que el continente africano no es tan pobre como uno podría imaginarse aunque, como veremos, la gente sí es extremadamente pobre. En cuanto a reservas naturales, África es una de las regiones más ricas del mundo, habiéndose calculado hasta ahora que posee el $75 \%$ del cobalto, el $46 \%$ de los diamantes, el 44\% del cromo, el 32\% del magnesio, el $32 \%$ del oro, el $24 \%$ de los fosfatos, el $20 \%$ del uranio, el $14 \%$ del cobre y el $11 \%$ del petróleo. De entre los productos agrícolas posee el $55 \%$ del cacao del mundo, el $19 \%$ del cacahuete y el $19 \%$ del café. Sus caladeros son enormes y muy apreciados en Europa como sabe muy bien nuestra flota pesquera.

Si volvemosnuestra atención de laeconomía a la cultura de Áfricahemos deadmitir que elmundo occidental sabe muy poco de las producciones artísticas y culturales del continente negro. Como dice el antropólogo Gustau Nerin (2): «África se ha visto inmersa en el mercado cultural mundial. Pero este mercado, como todo mercado, no sóloserige porpautas de calidad, sinoque depende de lógicas comerciales y financieras. Las producciones culturales funcionan, en realidad, como simples mercancías que aportan beneficios aquienes crean y aquienes gestionan». Y es que la creación artística africana no se encuentra dentro de los grandes circuitos comerciales del arte (grandes editoriales, estudios de cine o firmas discográficas) y, por tanto, el resultado es doble:

(2) G. Nerin (1999) «Las masas africanas y la cultura de masas» en A. CASTEL (Coord.), El África que viene. INTERMON, Barcelona, p. 45 
por una parte África está siendo invadida por las expresiones culturales de los países ricos de occidente y, por otra, occidente recibe muy poca información sobre las expresiones culturales y artísticas del continenteafricanoque son muy poco conocidas, aexcepción de algunos autores literarios como los tres premios Nobel de literaturael nigeriano Wole Soyinka, el egipcio Naguib Mahfouz y la sudafricana Nadime Gordimer, o el filósofo poeta Léopold Senghor, junto a algunas manifestaciones artísticas de tipo popular...

Finalmente, adentrándonos un poco en el alma del pueblo africano, lo primero que descubrimos es algo totalmente distinto a lo que caracteriza la sociedad occidental. Mientras nosotros los europeos hemos separado claramente lo religioso de lo no religioso, lo vivo de lo muerto, el hombre del mundo físico que lo rodea, en África estas dicotomías no se entienden; para ellos el hombre, los muertos, la naturaleza y Dios forman un todo inseparable. «Como una atmósfera que envuelve e ilumina el mundo; la vida del hombre, la naturaleza con todos sus fenómenos, el pasado, el presente y el porvenir... todos tienen su carácter fundamentalmente religioso y sacro. Para el negro africano ontología y religión se identifican o al menos son inseparables» (3). Y un filósofo africano, J. Mbiti, escribe (4): «...la religión es un fenómeno ontológico que forma parte del problema de existir y ser. Paraél (africano), vivires tomar parte en un drama religioso. El mundo en que vive y todas las actividades que desarrolla son vistos a través de un prisma y una significación religiosa... Toda la existencia es para el negro africano un fenómeno religioso. El hombre es un ser religioso que vive en un mundo religioso». Y el antropólogo francés Marcel Griaule, que ha conocido como pocos al pueblo Dogon de Mali, nos dice (5) que «estos hombres viven según una cosmogonía, una metafísica y una religión que les sitúa a la altura de los pueblos antiguos de occidente y que la misma cristología podría estudiar con provecho» (6). Este mismo autor insiste en la importancia primordial de la noción de persona relacionada con la sociedad, el universo y la divinidad: «...la civilización dogon aparece como una civilización del verbo. La naturaleza de la palabra, su origen divino, su papel a la vez metafísico

(3) M. Combarros (1993), «Dios en África. Valores de la tradición bantú». Mundo Negro. Madrid. p. 37.

(4) J. Мвіті (1972), Religions et philosophie africaines. Yaoundé, 1972, p. 24.

(5) M. Griaule (1987), Dios de Agua. Ed. Alta Fulla. Barcelona p. 36.

(6) Idem. 
y social, sus relaciones con los elementos del cosmos y de la persona» (7). Y un último testimonio sobre el carácter religioso del mundo africano: «Todo el universo físico y espiritual del africano está impregnado de una gran variedad de espíritus y fuerzas invisibles. El vudú del África occidental es la expresión mejor organizada de un mundo que se mueve entre la apariencia de lo que se ve y la realidad ultrahumana. Allí, los antepasados, las fuerzas invisibles y los vudús mediadores pueden coexistir con el gran Dios creador» (8).

Otros valores humanos que pueden encontrarse en el África negra son el respeto a la vida, que es sagrada, la defensa de la naturaleza, el acatamiento a la autoridad, el cuidado de los ancianos, la hospitalidad, la solidaridad dentro del clan, la alegría de vivir que se manifiesta en su amor a la música, la danza o a las representaciones teatrales, etc. etc.

\section{Sombras de África}

Pero, comoen un cuadrode Rembrandt, en el que aparecen fuertemente marcados los claroscuros, también en África hay sombras, y muy oscuras, que ahora hemos de mostrar para luego analizar sus causas y proponer algunas líneas de acción para, ya que no se pueden suprimir de inmediato, al menos ir suavizándolas.

Ahí van algunos fríos datos estadísticos:

\begin{tabular}{|l|c|c|c|}
\hline Conceptos & Mali & África & $\begin{array}{c}\text { Países } \\
\text { industrializados }\end{array}$ \\
\hline Esperanzade vidaal nacer & 53,4 & 48,9 & 77,7 \\
\hline Tasadealfabetización & 35,5 & 58,5 & 98,7 \\
\hline PIB percápita en dólares/año & 740 & 1.534 & 23.741 \\
\hline Tasamortalidad:lactantes/1.000 nacidosvivos & 145 & 105 & 6 \\
\hline Tasamortalidadmenores de5 años/1.000nacidos & 239 & 169 & 7 \\
\hline Tasamortalidadmaterna/100.000nacidosvivos & 1.200 & 979 & 13 \\
\hline Médicos/100.000habitantes & 4 & 16 & 356 \\
\hline Enfermeras/100.000habitantes & 9 & 75 & 813 \\
\hline
\end{tabular}

(7) G. CALAME-Griaule; en el prólogo al libro de su marido «Dios de Agua», p.7.

(8) Idem. 
Estas cifras son muy frías. La dura realidad es que hay millones de hombres y mujeres en África que viven con unos céntimos al día (en Mali un salario normal puede ser de 7.000 ptas /mes) que, si no mueren de hambre, lo hacen de mala nutrición antes de los 40 años, que millones de niños mueren al nacer o en los cinco primeros años de sus vidas; esto significa que 22 millones de personas están infectadas actualmente en África del SIDA y que el año pasado murieron a causa de esta enfermedad un millón y medio de personas. El SIDA ya no es sólo un problema de salud, es un freno al desarrollo económico de estos países y una amenaza a todo el tejido social del continente africano. El SIDA y otras enfermedades exigen enormes gastos en sanidad lo que sólo puede hacerse en un país pobre restando estos dineros de los presupuestos de educación, infraestructuras y desarrollo industrial.

Estas cifras reflejan una economía de subsistencia, una incapacidad total para entrar en los flujos normales de financiación o de intercambiocomercial; significan una total incapacidad para hacer frente a los gastos corrientes del Estado que tienen que cubrirse con préstamos que luego no pueden pagar. Estas cifras, en fin, significan el subdesarrollo del que tanto oímos hablar y tan poco sabemos. Y la pregunta que nos podemos hacer es: ¿cómo ha llegado África a esta situación? Intentemos dar una respuesta.

África ha llegado a este estado de total postración debido a siglos de esclavitud: primero, esclavitud humana, luego, esclavitud politica y, ahora, esclavitud económica.

\section{a) Esclavitud humana: la trata de esclavos}

La trata de esclavos negros ha sido una constante de muchos países del continente africano a través de la historia y hasta tiempos muy recientes. En un enorme continente escasamente poblado, la propiedad privada de la tierra no tenía mucho sentido. El clan ola tribu limpiaba un trozo de selva, quemaba los rastrojos cuyas cenizas abonaban el suelo para cultivar el grano necesario para cubrir sus necesidades alimenticias y, cuando el suelo había sido agotado, loúnico que tenían que hacer era moverse un poco más lejos hasta encontrar otro terreno en el que repetir el mismo proceso. Había tierra para todos, lo que se necesitaban eran brazos para cultivarla, lo que puede explicar el deseo de tener hijos varones y, si éstos no bastaban, comprar otros brazos de esclavos en el mercado o conseguirlos como 
prisioneros en la guerra.

Cuando los pueblos islámicos entraron en contacto con los pueblos negros del surdel Sahara tuvieron también que comprar mano de obra para cultivar sus fértiles campos del Magreb o del Oriente Medio. Pero los cristianos no fueron mejores que los mahometanos. El portugués Antonio Gonzálezllegóa Guinea 58 años antes del descubrimiento de América e hizo prisioneros que vendió como esclavos, iniciándose así un floreciente mercado de esclavos en Lisboa y Sevilla.

La aceptación, después de muchas discusiones entre los eruditos de Salamanca, de que los indios de América tenían alma, y la defensa que hizo de ellos Fray Bartolomé de las Casas, forzó a las autoridades españolas a controlar los abusos que se cometían con los nativos americanos; para sustituir a los indios protegidos permitieron que se importasen negros de África. En 1511 Fernando I el Católico hizo llegar a América un lote de varios cientos de negros y, cinco años más tarde, Carlos $\mathrm{V}$ concedió a un comerciante flamenco el privilegio de llevar a las Américas 400 negros al año, privilegio que este vendió por 25.000 ducados a un genovés, organizándose así de forma regular el comercio de esclavos, primero por los españoles y luego, principalmente, por los ingleses y franceses.

Este tráfico humano estaba integrado en un sistema de comercio llamado «triangular»: se traían de Europa tejidos, armas, alcohol y chucherías con las que se compraban los esclavos en África; estos eran transportados a las Américas, y con los beneficios de su venta se compraban productos tropicales americanos, especialmente azúcar, que se llevaba a Europa. No se puede saber a ciencia cierta cuántos hombres y mujeres africanos fueron vendidos como esclavos, se habla de unos 14 millones a los países islámicos y de 20 a 30 millones a los europeos. Y no fue hasta el siglo pasado que se puso fin a este comercio inhumano. Gran Bretaña abolió la esclavitud en 1807; en España en 1867 se empezó a castigar el comercio de negros y en 1880 se abolió definitivamente la esclavitud en los dominios españoles. Y fue sólo en 1888 cuando la Iglesia, por boca del Papa León XIII, declaró en la Encíclica «In Primis» que la trata de esclavos se oponía a las leyes divinas y humanas.

Cincuenta millones de hombres y mujeres arrancados de sus hogares y sus tierras, además de los muchos otros que morirían en esta caza humana; esta gran sangría humana tenía necesariamente que producir un terrible impacto en el continente africano. Pero cuando aquellas gentes pudieron creer que la terrible 
esclavitud había terminado, otra tan mala o peor empezó. En noviembre de 1885 las potencias europeas reunidas en Berlín pusieron las bases para la división entre ellas del continente africano, reconociendo al mismo tiempo la propiedad privada, a título personal, del rey Leopoldo II de Bélgica sobre el territorio del Congo, e iniciándose así la nueva forma de esclavitud del pueblo africano que conocemos comoel «colonialismo».

\section{b) La esclavitud política: el colonialismo}

Los efectos del colonialismo fueron desastrosos tanto para la sociedad como para la economía de África. Cada potencia europea, una vez en posesión de un territorio de África, bien conquistado por las armas o bien comprado, lo encerraba en unas fronteras que cortaban con frecuencia los grupos naturales de la sociedad africana. Ya hemos visto que en aquel continente laidea de propiedad de la tierra o de territorialidad no tiene ningún sentido. La sociedad estaba organizada, no sobre territorios autónomos, sino sobre grupos humanos: la raza, el grupo étnico, el clan, el linaje y el individuo. Las fronteras de los nuevos Estados establecidos por las potencias coloniales cortaban todos estos grupos naturales creando conglomerados de grupos étnicos, clanes y tribus, que no sólo no tenían nada en común sino que con frecuencia tenían una historia de enfrentamientos entre ellos. Esto puede explicar las terribles luchas tribales que todavía se dan en muchos países africanos.

En Ruanda, por ejemplo, cuando los belgas se apoderaron del país, se apoyaron en el «mwami» (rey) y la élite tradicional hutu del Norte perdió casi todo su poder y sus prerrogativas en provecho de la aristocracia tutsi venida del Sur con el apoyo de la administración colonial y de la Iglesia Católica, continuándose así un sistema feudal en el que la minoría tutsi dominaba a la mayoría hutu.. Pero de 1959 a 1962 Ruanda conoció una revolución social que cambió profundamente el país. Se publicó el «Manifiesto Hutu» que denunciaba el monopolio político, económico, social y cultural de la minoritaria etnia tutsi, mientras que la administración belga y la Iglesia cambiaban su política y se alineaban del lado de los hutus, los cuales se pudieron finalmente hacer con el poder. Las graves consecuencias de estas políticas de fomento de las diferencias étnicas o tribales se vieron en el terrible genocidio de los tutsis en 1994, en la actual persecución de los hutus por parte de los tutsis y en la caótica situación 
que se vive hoy en toda la región de los Grandes Lagos (9).

Un autor africano, Donato Ndondo-Bidyogo, nos da una negra imagen de lo que supuso el colonialismo para la sociedad africana (10): «Con el colonialismo se empezará a regular la vida del africano según los cánones de los opresores: se les vació de toda identidad y de toda autoestima, al convencerles que sus costumbres eran salvajes, que no tenían cultura ni historia; en el África colonial la palabra civilización estaba reservada exclusivamente a los comportamientos de los blancos, por muy crueles que fuesen» y el actual Presidente de la Unión Sudafricana, Thabo Mbeki, describe los efectos trágicos del colonialismo con estas palabras (11): «Para perpetuar su dominación imperial sobre los pueblos de África, los colonizadores procuraron reducir a esclavitud al mismo espíritu africano y destruir la propia alma africana. Nos obligaron a aceptar el hecho de que, en cuanto africanos, no teníamos nada que aportar a la civilización humana, a no ser como bestias de carga. A fin de cuentas, querían conducirnos a despreciarnos a nosotros mismos. Y cuando estuvieron dispuestos a admitir que no éramos infrahumanos, ni siquiera contemplaron la posibilidad de que pudiéramos compararnos con el amo colonial. A sus ojos, estabamos desprovistos del pensamiento original y de la creatividad que ha dado al mundo ese inestimable tesoro de las obras maestras arquitectónicas y artísticas».

A esta descomposición de la sociedad africana se unió una total destrucción del sistema económico prevalente. El reparto de África se hizo en el mismo momento en que los países europeos estaban embarcados en un rápido proceso de industrialización y que, por tanto, necesitaban urgentemente dos cosas: materias primas y mercados donde vender sus productos, y esto se lo proporcionaban las colonias de África. Se descuidó la modernización de las pequeñas explotaciones agrarias productoras de alimentos y se puso el énfasis en la producción minera,

(9) Para una descripción sobrecogedora de la tragedia de Ruanda puede leerse el libro del sacerdote-periodista-teólogo André Sibomana, que murió en 1998 al negarle el gobierno tutsi el visado para salir del país para curarse de una grave enfermedad. A. Sibomana (1999), Mantengamos la esperanza en Ruanda. Conversaciones con Laure Guilbert y Hervé Deguine. Ed. Mundo Negro. Madrid.

(10) D. Ndondo-Bidyogo (1999). «Conflictos en África» en A. CASTEl (Coord.), El África que viene. Ed. INTERMON. Barcelona, p. 276.

(11) T. Mвекi (1999), «África: elogio de la rebelión». En Envío. Revista de la UCA de Managua. agosto de 1999, p. 25. 
en la creación de grandes explotaciones agrarias de cultivos comerciales comoel algodón, el café o el cacao, y en la construcción de unas infraestructuras de comunicaciones, no con vistas al desarrollo del país sino, únicamente, a facilitar el transporte de los productos exportables a Europa.

Pero quizás el peor impacto que tuvo el colonialismo sobre la sociedad africana fue en el campo de la educación. Los poderes coloniales sabían bien que no hay nada más peligroso que un esclavo educado y, por tanto, intentaron por todos los medios que los africanos nollegasen a un nivel educativo que pudiese ser peligroso para los poderes fácticos. En muchas de las colonias de África las universidades estaban cerradas a los jóvenes negros. Y cuando, después de cien años de administración colonial, estos países europeos abandonaron África, dejaron países con niveles de analfabetismo del $80 \%$ de la población y sin una clase intelectual y profesional suficientemente preparada para afrontar los tremendos retos políticos, económicos y sociales de los recién nacidos estados independientes. Cuando nos escandalizamos de la mala gestión y la corrupción de algunos gobiernos africanos, deberíamos preguntarnos ¿qué hizo Europa durante más de cien años de dominación colonial para formar una elite que pudiese dirigir el país?

En la década de los 60 tres factores impulsaron los movimientos independentistas de la mayoría de las colonias africanas: el debilitamiento de las potencias dominantes (especialmente Inglaterra y Francia), la guerra fría que hizo que las dos superpotencias, Estados Unidos y Rusia, se volcasen sobre África, aparentemente para ayudar a estos países a alcanzar la independencia, pero, en verdad, para conseguir ventajas geopolíticas sobre el adversario, y el nacimiento de un nuevo sentimiento de autoestima de las poblaciones negras que se manifestó con el movimiento cultural de la «negritud». Pero para la mayoría de estos países la independencia fue, como dice el refrán español, «caer de la sartén al fuego», librándose de la esclavitud política para caer en una nueva esclavitud económica que conocemos como neo-colonialismo.

\section{c) Esclavitud económica: el neo-colonialismo}

El neocolonialismo es otra forma más sutil, pero no por eso menos dolorosa que el colonialismo, de dominación de unos pocos países ricos sobre muchos países pobres. En el neocolonialismo no se utilizan las armas de fuego para dominar al más débil, sino las armas económicas del comercio y las finanzas que crean una 
total dependencia de todos los aspectos de la vida del país más pobre de la voluntad del país rico. En la nueva forma de colonialismo se mantienen los mismos injustos mecanismos de intercambio tecnológico, comercial y cultural que en el sistema anterior: los países sometidos, con tecnología adquirida de los países ricos, producen y suministran a estos países las materias primas que estos necesitan y que luego venden otra vez a los pobres transformadas en bienes de consumo. Los países pobres son incapaces, dados los bajos precios que reciben por sus materias primas, de acumular el suficiente capital que necesitan para poder dedicarlo al desarrollo del país y, por tanto, se ven obligados a acudir a las instituciones financieras de los países desarrollados en busca de créditos con intereses «usureros» que difícilmente podrá devolver, lo que aumenta necesariamente la situación de sometimiento de estas antiguas colonias hoy teóricamente independientes. El famoso obispo de Brasil, Pedro Casaldáliga, dice que «la deuda externa ha sido y es el arma más mortal que ha conocido la humanidad. Mantener la deuda externa es un crimen contra la humanidad, es un pecado mortal, porque realmente mata, porque mientras se paga la deuda externa no se puede pagar la deuda social».

La deuda externa afecta a todos los países en vías de desarrollo, pero principalmente a los países del sur del Sahara. De los 42 países clasificados por el Banco Mundial como altamente endeudados, 33 son del África subsahariana. La deuda externa de estos países ha ido subiendo de 3.000 millones de dólares en 1962 a 142.000 millones en 1980 y 235.000 millones en 1996. En unos países en que la renta per cápita media es de 496 dólares, la deuda per cápita llega a 379 dólares, o sea que si pagasen a los acreedores les quedarían 117 dólares por persona por año. Naturalmente esto no lo pueden hacer y entonces la única solución para muchos de estos países es pedir más créditos para poder pagar, si no el principal al menos los intereses de la deuda acumulada. África, por cada dólar de ayuda exterior que recibe desembolsa tres dólares para pagar únicamente los intereses de la deuda. Y todos estos dineros que se utilizan para pagar la deuda se tienen necesariamente que sustraer de otras partidas no productivas como la educación o la salud. Pero con menos salud y menos educación las posibilidades de librarse de la argolla de la deuda disminuyen, quedando estos países atrapados en el círculo vicioso de la pobreza: más pobres - menos salud y menos educación - menos producción - menos ventas - más pobreza. ¿Cómo romper este dilema: deuda externa $=$ deuda eterna?

No quiero terminar esta intervención sin ofrecer, si no soluciones, al menos 
líneas de pensamiento sobre las posibilidades de desarrollo de estos países africanos. Y está claro que el camino de liberación de estos países de las esclavitudes que los aplastan es a largo plazo, ni más ni menos, que la educación.

\section{Respuestas al reto africano}

En una reciente conferencia, el profesor Rubens Ricupero, Secretario General de la UNCTAD criticaba el paradigma de desarrollo prevalente durante los últimos 15 años y que hainspirado las medidas estructurales exigidas por el Banco Mundial y el Fondo Monetario Internacional a los países endeudados para hacerse acreedores de nuevas ayudas. Estas medidas eran eminentemente macroeconómicas y son conocidas por todos: control de la inflación, reducción del déficit publico, liberalización del comercio y las finanzas, limitación del papel del Estado en la economía a favor del papel del mercado. Sin embargo, la experiencia ha mostrado que este enfoque es demasiado estrecho y con frecuencia lleva a un empobrecimiento real de las poblaciones de los países a alos que se quiere ayudar. En el seno mismo del Banco Mundial se han oído voces críticas a este limitado punto de vista, y el hasta hace poco su principal economista jefe, el profesor Joseph Stiglitz ha forzado a esta institución a adoptar un nuevo enfoque al problema del desarrollo, el llamado «marco estratégico global para el desarrollo» que incluye aspectos meta-económicos como la reforma de algunas instituciones sociales, la mejora del marco legal y la potenciación de un gobierno mejor.

Este nuevo enfoque del Banco Mundial se ha visto reflejado en el último «Informe sobre el desarrollo mundial» (12) que ha sido dedicado al análisis de un factor hasta ahora considerado sin valor económico, como es el «conocimiento», y su influencia en el desarrollo de los países más pobres. El Informe se titula «El conocimiento al servicio del desarrollo» y quiero terminar esta exposición sobre África con unas palabras de este Informe que creo dan una pista clara sobre el camino a seguir por estos países africanos para finalmente librarse de todas las esclavitudes que hasta ahora los han tenido sometidos.

El informe empieza con esas hermosas palabras: «El conocimiento se asemeja a la luz. Su ingravidez e intangibilidad le permiten llegar sin dificultad a todos los

(12) Banco Mundial (1999), Informe sobre el desarrollo mundial. El Conocimiento al servicio del desarrollo. Ed. Mundi-Prensa. Madrid. 
confines eiluminar la vida de los seres humanos en todoel mundo. A pesar de ello, miles de millones de personas viven todavía sumidas en la oscuridad de la pobreza»; y continúa: «lo que distingue a los pobres -sean personas o países-de los ricos es no sólo que tienen menos capital sino también menos conocimientos... El conocimientoilumina todas las transacciones económicas: revela las preferencias, aclara los intercambios, orienta los mercados. Por el contrario, la falta de conocimiento es el factor que provoca el desplome de los mercados o impide su aparición». Para el desarrollo de un país es necesario adquirir conocimientos a través de la investigación y, como recuerda el Banco Mundial, escuchando a los pobres que tienen mucho que decir; aprender conocimientos a través de la educación a todos los niveles, y comunicar conocimientos a través de las nuevas tecnologías de la información y las comunicaciones.

Creo que este es el mejor mensaje que os podéis llevar con vosotros al final de vuestra carrera. Seguid adquiriendo conocimientos con la investigación, aprended nuevos conocimientos ya existentes con el estudio, pero no guardéis para vosotros solos todo lo aprendido: comunicad estos conocimientos a los otros, principalmente a los pobres. Haced que aquellos que no han tenido vuestras oportunidades de estudio puedan aprovecharse de vuestros conocimientos compartiéndolos con ellos. Dar dinero para África es difícil, dar vuestro tiempo a un proyecto de África es más difícil, pero dar vuestros conocimientos es lo más difícil y, sin embargo, lo más útil. Hay Médicos sin fronteras, Veterinarios sin fronteras, Farmacéuticos sin fronteras, Bomberos sin fronteras, Payasos sin fronteras, y yo pregunto ¿por qué no puede haber «Empresarios sin fronteras»: jóvenes que, terminados sus estudios de ciencias empresariales, u hombres y mujeres adultos después de unos años de experiencia en el trabajo, dedican un año de su vida a ayudar a crear, a organizar o a gestionar una pequeña o mediana empresa en África? La pregunta esta ahí. Vosotros tenéis la respuesta. 